\title{
UIII Snow and Ice Removal Route Optimization in Kentucky
}

Kentucky Transportation Center Research Report - KTC-17-18/SPR16-529-1F

DOI: https://doi.org/10.13023/KTC.RR.2017.18

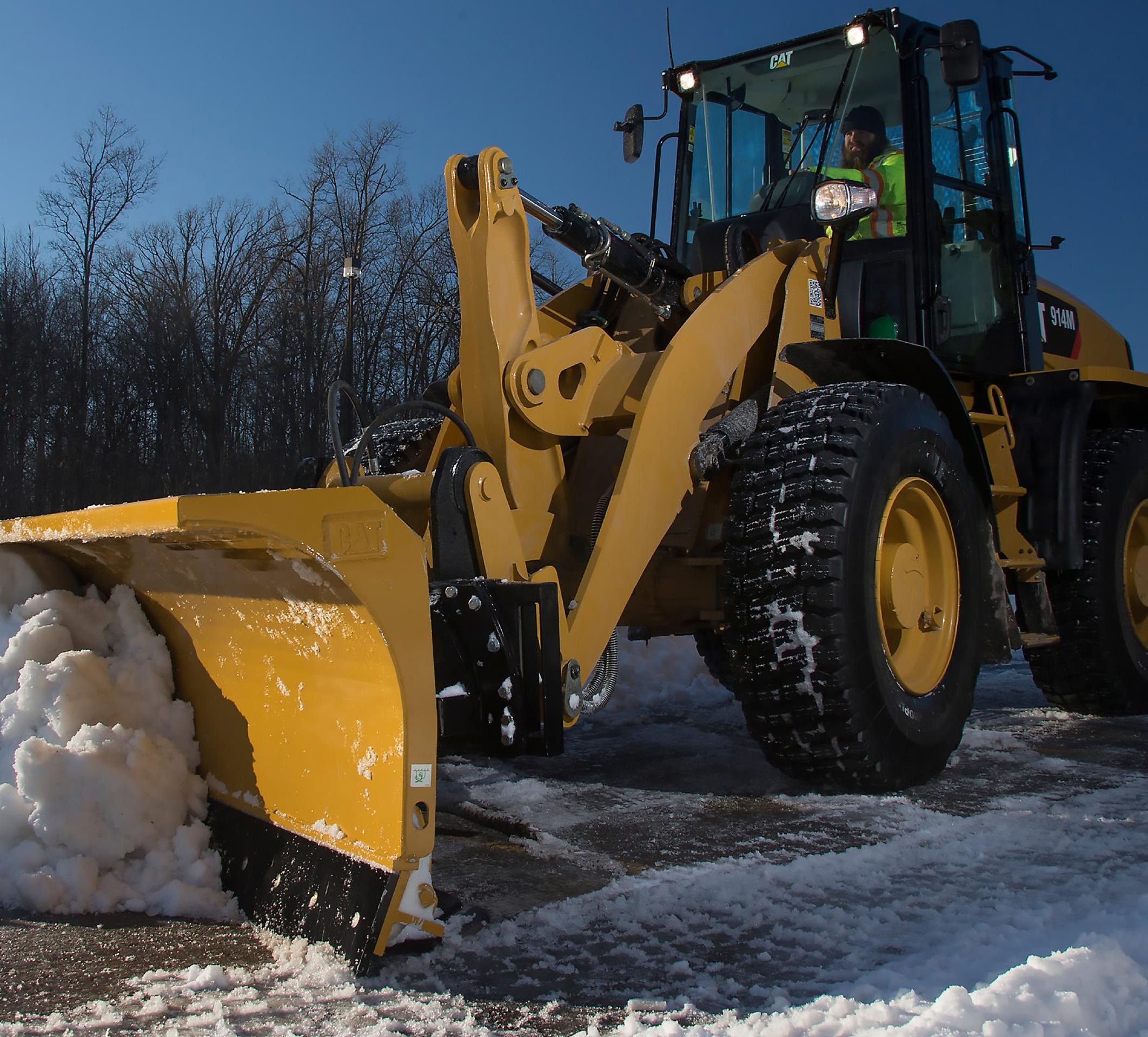




\section{KTC's Mission}

We provide services to the transportation community through research, technology transfer, and education. We create and participate in partnerships to promote safe and effective transportation systems. 


\author{
Research Report \\ KTC-17-18/SPR16-529-1F
}

\title{
Snow and Ice Removal Route Optimization in Kentucky
}

Benjamin Blandford, Ph.D.

Research Scientist

Erin Lammers

Research Engineer

And

Eric Green, P.E., MSCE

Research Engineer

\author{
Kentucky Transportation Center \\ College of Engineering \\ University of Kentucky \\ Lexington, Kentucky
}

\section{In Cooperation With}

Kentucky Transportation Cabinet

Commonwealth of Kentucky

\begin{abstract}
The contents of this report reflect the views of the authors, who are responsible for the facts and accuracy of the data presented herein. The contents do not necessarily reflect the official views or policies of the University of Kentucky, the Kentucky Transportation Center, the Kentucky Transportation Cabinet, the United States Department of Transportation, or the Federal Highway Administration. This report does not constitute a standard, specification, or regulation. The inclusion of manufacturer names or trade names is for identification purposes and should not be considered an endorsement.
\end{abstract}

August 2017 


\begin{tabular}{|c|c|c|c|}
\hline $\begin{array}{l}\text { 1. Report No. } \\
\text { KTC-17-18/SPR16-529-1F }\end{array}$ & 2. Government Accession No. & \multicolumn{2}{|c|}{ 3. Recipient's Catalog No } \\
\hline \multirow{2}{*}{\multicolumn{2}{|c|}{$\begin{array}{l}\text { 4. Title and Subtitle } \\
\text { Snow and Ice Removal Route Optimization in Kentucky }\end{array}$}} & \multicolumn{2}{|l|}{$\begin{array}{l}\text { 5. Report Date } \\
\text { August } 2017\end{array}$} \\
\hline & & \multicolumn{2}{|c|}{ 6. Performing Organization Code } \\
\hline \multicolumn{2}{|c|}{$\begin{array}{l}\text { 7. Author(s): } \\
\text { Benjamin Blandford, Erin Lammers, Eric Green }\end{array}$} & \multicolumn{2}{|c|}{$\begin{array}{l}\text { 8. Performing Organization Report No. } \\
\text { KTC-17-18/SPR16-529-1F }\end{array}$} \\
\hline \multirow{2}{*}{\multicolumn{2}{|c|}{$\begin{array}{l}\text { 9. Performing Organization Name and Address } \\
\text { Kentucky Transportation Center } \\
\text { College of Engineering } \\
\text { University of Kentucky } \\
\text { Lexington, KY 40506-0281 }\end{array}$}} & \multicolumn{2}{|c|}{ 10. Work Unit No. (TRAIS) } \\
\hline & & \multicolumn{2}{|c|}{$\begin{array}{l}\text { 11. Contract or Grant No. } \\
\text { SPR } 16-529\end{array}$} \\
\hline \multirow{2}{*}{\multicolumn{2}{|c|}{$\begin{array}{l}\text { 12. Sponsoring Agency Name and Address } \\
\text { Kentucky Transportation Cabinet } \\
\text { State Office Building } \\
\text { Frankfort, KY } 40622\end{array}$}} & \multicolumn{2}{|c|}{ 13. Type of Report and Period Covered } \\
\hline & & \multicolumn{2}{|c|}{ 14. Sponsoring Agency Code } \\
\hline \multicolumn{4}{|c|}{$\begin{array}{l}\text { 15. Supplementary Notes } \\
\text { Prepared in cooperation with the Kentucky Transportation Cabinet }\end{array}$} \\
\hline \multicolumn{4}{|c|}{$\begin{array}{l}\text { 16. Abstract } \\
\text { Each year the Kentucky Transportation Cabinet (KYTC) spends } \$ 40-\$ 80 \text { million removing snow and ice from the state's } \\
\text { roadways. Snow and ice removal are accomplished through a system of snow and ice removal routes that are designed to } \\
\text { account for location and the attributes of trucks, facilities, materials, and roadways. To identify strategies that will improve } \\
\text { and optimize KYTC's snow and ice removal operations, Kentucky Transportation Center (KTC) researchers used ArcGIS } \\
\text { and its Network Analyst extension to study the performance of the Cabinet's current routing procedures. Building from } \\
\text { this investigation, researchers developed optimized snowplow routings for four counties located in KYTC Districts } 6 \text { and } \\
7 \text { using Arc's Network Analyst and the Vehicle Routing Problem toolset. Optimized routings were developed for } \\
\text { individual counties, with snowplows assigned to routes based on truck type and route priority. Researchers experimented } \\
\text { with several routing iterations before arriving at a final version. The routing solution developed will result in KYTC being } \\
\text { able to treat all roadways using fewer trucks. Once successfully implemented, the potential cost savings - for the four } \\
\text { counties in which optimized routings were developed - could reach } \$ 225,000 \text { per year. Generating optimized routings } \\
\text { throughout the state of Kentucky could potentially result in millions of dollars saved for the Cabinet. }\end{array}$} \\
\hline $\begin{array}{l}\text { 17. Key Words } \\
\text { snow removal, ice removal, vehicle } \\
\text { route optimization }\end{array}$ & outing problem, network analyst, GIS, & $\begin{array}{l}\text { 18. Distribution } \\
\text { Unlimited }\end{array}$ & ment \\
\hline $\begin{array}{l}\text { 19. Security Classification (report) } \\
\text { Unclassified }\end{array}$ & $\begin{array}{l}\text { 20. Security Classification (this page) } \\
\text { Unclassified }\end{array}$ & $\begin{array}{l}\text { 21. No. of Pages } \\
30\end{array}$ & \begin{tabular}{|l|} 
19. Security \\
Classification \\
(report)
\end{tabular} \\
\hline
\end{tabular}




\section{Table of Contents}

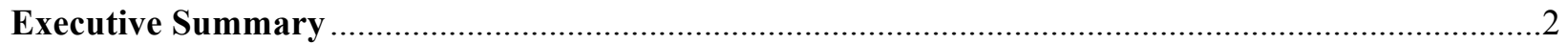

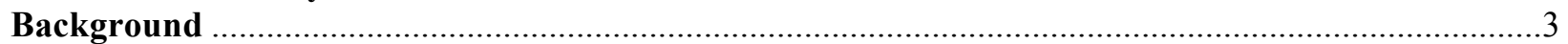

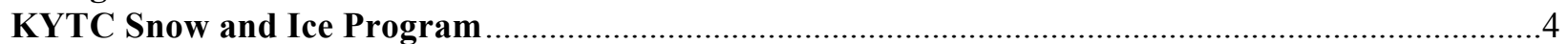

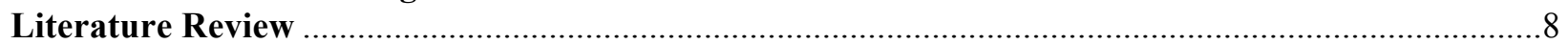

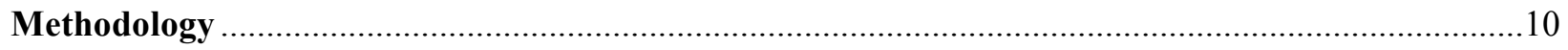

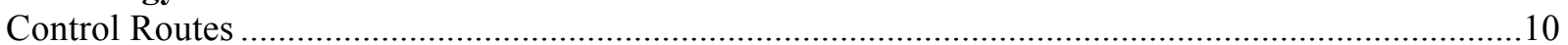

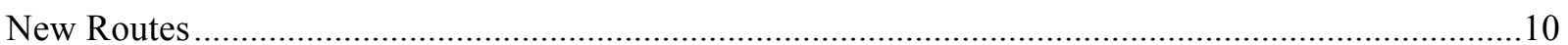

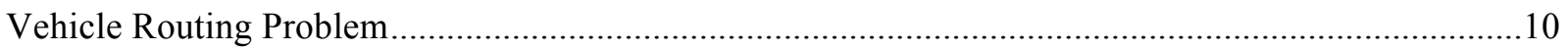

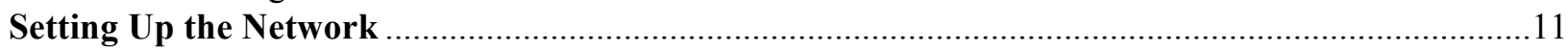

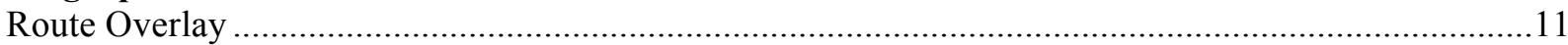

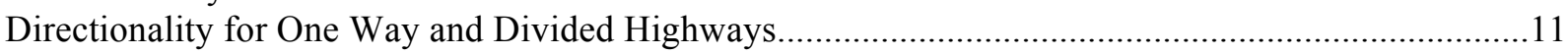

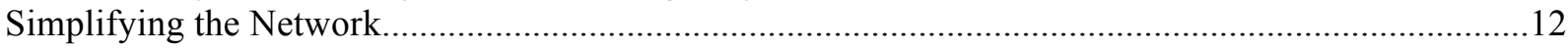

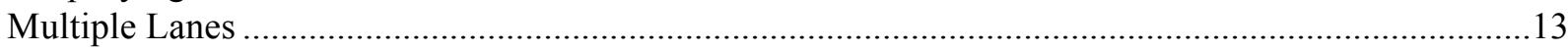

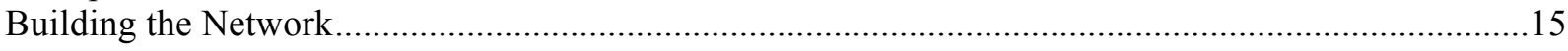

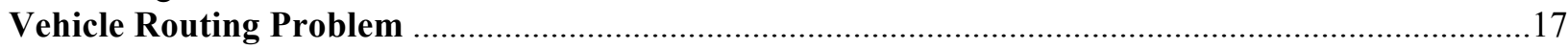

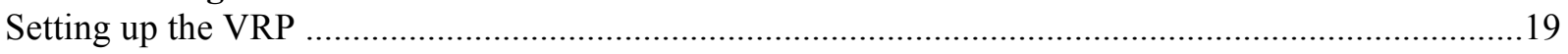

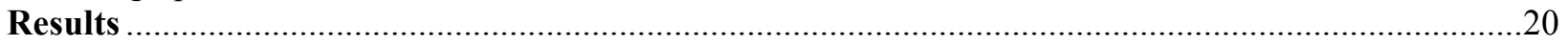

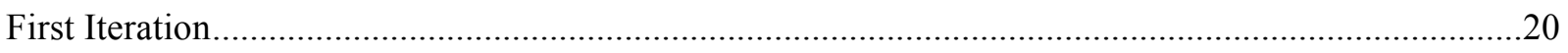

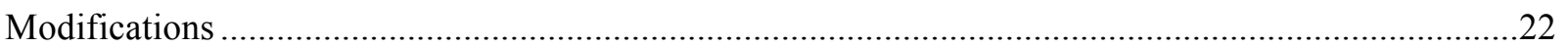

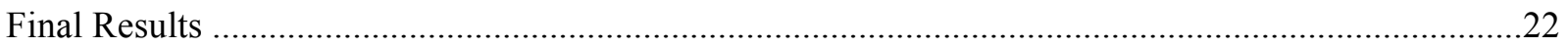

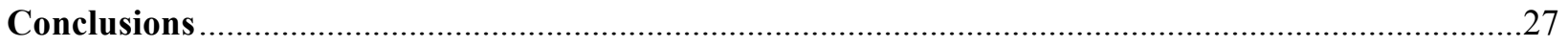

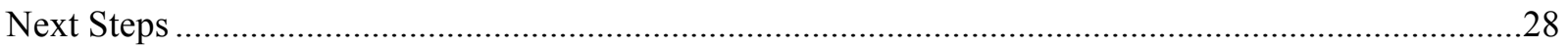

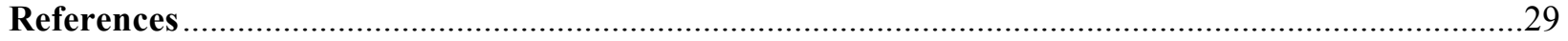

\section{List of Figures}

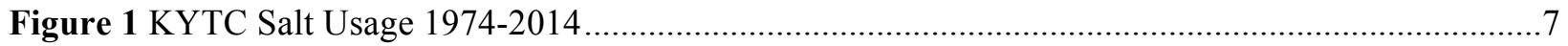

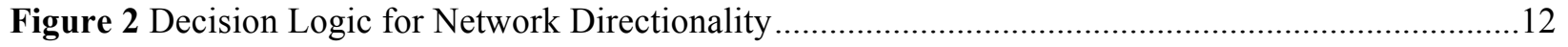

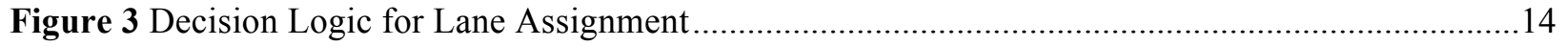

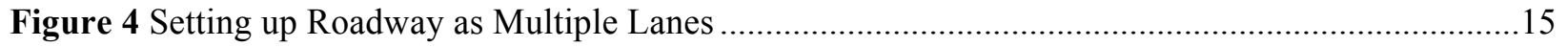

Figure 5 "Delivery" Points for Salt on Either Side of Roadway ….......................................................17

Figure 6 Example of First Iteration of Route Optimization (Anderson County) ....................................21

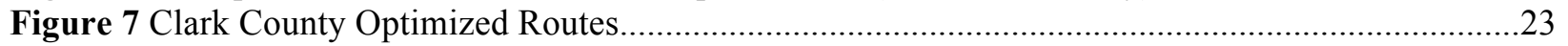

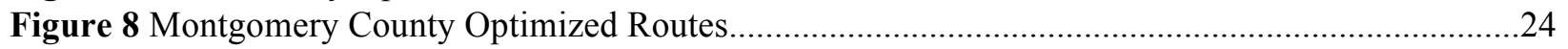

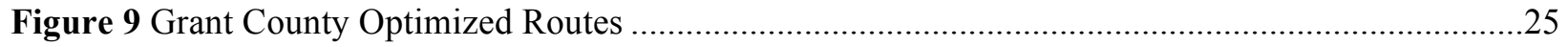

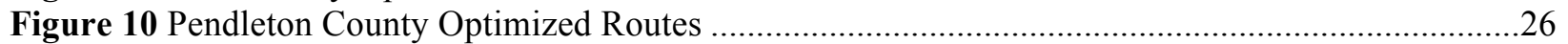

\section{List of Tables}

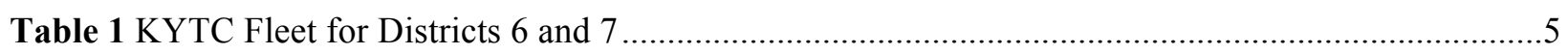

Table 2 Budgeted and Actual Snow and Ice Removal Costs ...............................................................6

Table 3 Salt, Brine, and Calcium Chloride Usage ….......................................................................

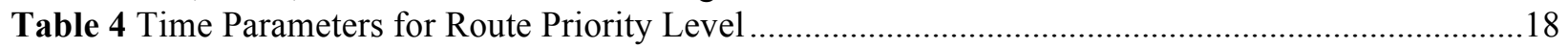

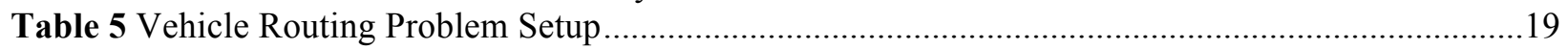

Table 6 Minutes to Treat All Routes per County (District 7) ................................................................20 


\section{Executive Summary}

This research describes a GIS-based methodology developed for the Kentucky Transportation Cabinet (KYTC) to improve the efficiency of Kentucky's snow and ice removal program. KYTC typically spends $\$ 40-\$ 80$ million annually on snow and ice removal and road treatments. This is accomplished through a system of snow and ice removal routes that must factor in the location and attributes of trucks, facilities, materials, and roadways. This research used ArcGIS and its Network Analyst extension to assess the performance of KYTC's current snowplow routing procedures and to identify strategies for optimizing them. Optimizing the routing system can improve efficiency, increase safety, and reduce the amount of time and funding needed to treat roadways during winter storms. This report documents the challenges, successes, and lessons learned from this research. Specific examples are provided to demonstrate the advantages of route optimization.

Kentucky Transportation Center (KTC) researchers developed optimized routings for four counties located in two of the state's highway districts. ESRI's Network Analyst and Vehicle Routing Problem toolset were used for this process. The optimizations were county-based, meaning that trucks were assigned to routes within counties based on truck type and route priority. This resulted in an optimized schedule of route treatment based on a typical storm. Early models achieved limited optimization, largely because there was a finite set of combinations based on route priority, truck type, and fleet assignments. Other issues with early models included overly complex routes and unrealistic treatment paths.

In subsequent models, researchers devised more optimal results by modeling routes at the multi-county or district level. This was conducted in highway districts 6 and 7 where truck fleets and salt/brine storage barns are shared among neighboring counties within the same district. KTC provided two districts with countylevel route maps based on the results of the district-wide optimization. With the new optimized routes, KYTC would be able to treat all routes on schedule and use fewer trucks in the process, leading to significant cost savings for KYTC. For Grant and Pendleton Counties in District 6, the model demonstrated the potential to eliminate six contract trucks, which would result in a cost savings of $\$ 25,000$ per truck per year. Similar results were found for Clark and Montgomery Counties in District 7, where route optimization demonstrated the potential to eliminate three contract trucks, with a similar cost savings of $\$ 25,000$ per truck per year. The potential cost savings in these four counties amounted to $\$ 225,000$ per year. 


\section{Background}

The Kentucky Transportation Cabinet (KYTC) manages a system of trucks and facilities used for snow and ice removal throughout the state of Kentucky. During a snow event, trucks follow established routes that have been used for decades. Currently, routes are largely county-based, with each county having a specific number of trucks and facilities available to address its needs. Routes in each county are divided into categories and prioritized based on several factors, with Average Annual Daily Traffic (AADT) being the most influential. Routes are cleared and treated within given timeframes based on their assigned priority.

While the current snow and ice treatment system is functionally effective, it has not been tested for efficiency. However, Geographic Information System (GIS) analytical tools have been used in many KYTC applications and have the potential to further optimize the snow and ice treatment system by offering an indepth examination of the network.

To this end, KYTC contracted the Kentucky Transportation Center (KTC) to perform a data-driven analysis of GIS-based methods to determine the feasibility of new methods. The purpose was to examine the current system and optimize truck routing throughout the network for a typical snow event. Key measures of optimization include time, location of fuel stations, salt availability, and number of trucks. The primary goals of KYTC were to improve efficiency, increase safety, and reduce the amount of time and funding needed to clear the roadways during winter storms. 


\section{KYTC Snow and Ice Program}

KYTC typically spends between $\$ 40$ and $\$ 80$ million per year on snow and ice removal and subsequent road treatment. For example, in FY2014, over $\$ 75$ million were spent on snow and ice removal. Of this sum, \$29 million went toward materials, \$20 million paid for contract equipment, \$17 million funded state labor, and $\$ 9$ million went toward the purchase of state equipment.

The goals of KYTC's snow and ice control program are to:

- Provide adequate traction on road surfaces

- Promote safe and timely driving conditions

- Provide uniformity of pavement conditions within the route priority system

- Account for economic and environmental factors

Each designated route receives a priority ranking before the onset of the winter season. Route maps are created at the highway district level (Kentucky is divided into 12 highway districts) and submitted to the KYTC Division of Maintenance for posting on KYTC's website. Designating route priority accounts for the following:

- Priority A: Includes interstates, parkways, Federal-aid primary routes, and road segments in the counties with ADT higher than that of the Federal-aid primary route in that county. Additionally, any non-federal aid secondary routes with an ADT greater than 1,000 may be included. Total Priority A mileage within a county should not be less than $20 \%$ and not more than $50 \%$ of the twolane road mileage within the county.

- Priority B: Includes Federal-aid secondary routes not designated as Priority A and routes having an ADT greater than 500. Total Priority B mileage within a county should not be less than $20 \%$ and not more than $50 \%$ of the two-lane road mileage within the county.

- Priority C: Includes all state-maintained routes not designated as Priority A or Priority B. Total Priority C mileage within a county should not be less than $20 \%$ and not more than $50 \%$ of the twolane road mileage within the county.

KYTC has established guidelines regarding how quickly and often routes must be treated:

- Interstates and parkways - including all mainline, distributor, and collector lanes and ramps should be treated every hour, as needed.

- All other A routes should be treated every 2 hours, as needed.

- B routes should be treated every 4 hours, as needed.

- $\quad$ routes should be treated every 8 hours, as needed ${ }^{1}$. Treatment of $\mathrm{C}$ routes can be deferred beyond the 8 -hour time window if storm conditions dictate that $\mathrm{A}$ and $\mathrm{B}$ routes require more extensive attention.

Each district has a designated number of state-owned and operated trucks to use for snow and ice removal. While the features of these trucks vary, they can be divided into two categories: tandem trucks and single axle trucks. Tandem trucks are larger and have a greater salt carrying capacity than single axle trucks. Because of their larger size, tandem trucks are not able to treat some rural C routes, particularly those with lanes that are too narrow or on roadways exposed to high winds. Only single axle trucks can treat these smaller rural routes.

\footnotetext{
${ }^{1}$ Since writing, protocol for $\mathrm{C}$ routes has changed. $\mathrm{C}$ routes are now treated every 16 hours and can be disregarded between the hours of 9:00pm and 5:00am if conditions warrant. This may change nuances of the new routes, but does not change methodology.
} 
In addition to the state-owned trucks, KYTC also contracts with private operators to treat roads during snow and ice events. Contract trucks are the largest in size and have the greatest salt carrying capacity. As a result, contract trucks are used solely on the largest highways with the widest lanes, including all interstates, parkways, and other major highways. Table 2 lists the number and types of trucks for each county in KYTC Districts 6 and 7. KYTC personnel from these two districts were included as part of the Study Advisory Committee, and because the research team was the most familiar with these districts, the initial research focused primarily on counties within these two districts. Tapping into their knowledge of the roadway network made for an ideal starting point.

Table 1 KYTC Fleet for Districts 6 and 7

\begin{tabular}{|l|l|l|l|l|l|l|l|}
\hline District 6 & $\begin{array}{l}\text { Single } \\
\text { Axle }\end{array}$ & Tandem & Contract & District 7 & $\begin{array}{l}\text { Single } \\
\text { Axle }\end{array}$ & Tandem & Contract \\
\hline Boone & 4 & 2 & 21 & Anderson & 3 & 2 & 6 \\
\hline Bracken & 3 & 2 & 3 & Bourbon & 3 & 1 & 5 \\
\hline Campbell & 4 & 1 & 8 & Boyle & 4 & 1 & 2 \\
\hline Carroll & 3 & 2 & 2 & Clark & 3 & 2 & 12 \\
\hline Gallatin & 4 & 2 & 4 & Fayette & 5 & 1 & 27 \\
\hline Grant & 4 & 3 & 7 & Garrard & 2 & 2 & 3 \\
\hline Harrison & 3 & 2 & 2 & Jessamine & 2 & 2 & 2 \\
\hline Kenton & 5 & 2 & 17 & Madison & 3 & 2 & 15 \\
\hline Owen & 4 & 2 & 1 & Mercer & 3 & 1 & 1 \\
\hline Pendleton & 4 & 1 & 2 & Montgomery & 3 & 1 & 4 \\
\hline Robertson & 3 & & & Scott & 6 & 1 & 14 \\
\hline & & & & Woodford & 3 & 1 & 2 \\
\hline D6 TOTAL & 41 & 19 & 67 & D7 TOTAL & 40 & 17 & 93 \\
\hline
\end{tabular}

Trucks generally operate at set speed limits to ensure safe and efficient clearing and treating. Speeds are set according to road type:

- For interstates, parkways, and major highways, truck speed is set at $30 \mathrm{mph}$

- For all other highways, including ramps, turning lanes, and rural state routes, truck speed is set at $15 \mathrm{mph}$

All control and new route calculations are based on the set speeds above. However, it is important to note that while plows attempt to stay at these speeds, there is sometimes discrepancy between planned speed and actual speed. Speed is often a function of the snowfall intensity. Time of day is also a factor. For instance, it is easier to move at top required speed at night when there is less traffic to maneuver through. Travelling too fast can adversely affect the distribution of salt. While $35 \mathrm{mph}$ is the maximum speed for ideal salt application, KYTC's Automatic Vehicle Location (AVL) data suggest that truck drivers unsafely travel at speeds as high as $51 \mathrm{mph}(82 \mathrm{~km} / \mathrm{hr})$ on interstates.

KYTC has a total statewide storage capacity for 314,000 tons of salt; salt is held at KYTC district and county highway maintenance facilities. The Mega Cavern, an underground facility in Louisville, contains the largest salt supply. It currently houses 180,000 tons of salt and serves as a reserve for districts across the state. When salt supplies run low, KYTC replenishes them from multiple contracted vendors.

Brine is applied to roadways before most winter weather events. The resulting salt residue is activated once precipitation falls. Brine is applied when the temperature of the road surface is at 20 degrees Fahrenheit 
and rising. It mitigates hazardous driving conditions and increases roadway safety during the early hours of a winter weather event by preventing the ice and snow from bonding to the road surface. Roadways are easier to clear once brine has been spread on them. In low temperatures, a calcium chloride solution is added to salt application to help melt snow and ice.

KYTC's vehicle and equipment fleet includes 980 snowplows. In addition, the Cabinet has recourse to 436 contracted snowplow trucks to assist with snow and ice removal. KYTC is responsible for more than 63,000 lane miles of roads. KYTC maintenance crews totaling nearly 2,000 employees work to keep roadways open in the winter. Table 2 lists the amounts budgeted for maintenance personnel, materials, and snow and ice removal operations and compares it to actual amounts spent.

Table 2 Budgeted and Actual Snow and Ice Removal Costs

\begin{tabular}{|l|c|c|c|c|c|}
\hline \multicolumn{1}{|c|}{ Maintenance } & $\mathbf{2 0 1 3}$ & $\mathbf{2 0 1 4}$ & $\mathbf{2 0 1 5}$ & $\mathbf{2 0 1 6}$ & $\mathbf{2 0 1 7}$ \\
\hline $\begin{array}{l}\text { Budget* } \\
\text { (overtime, materials, } \\
\text { and contracts only) }\end{array}$ & $\$ 27,500,000$ & $\$ 27,500,000$ & $\$ 27,500,000$ & $\$ 27,500,000$ & $\$ 27,500,000$ \\
\hline $\begin{array}{l}\text { Snow and Ice } \\
\text { Removal Costs } \\
\text { (actual)** } \\
\text { (includes regular } \\
\text { salaries and state } \\
\text { equipment charges) }\end{array}$ & $\$ 41,694,000$ & $\$ 75,232,921$ & $\$ 66,701,894$ & $\$ 58,529,000$ & $*$ \\
\hline
\end{tabular}

*Data currently not available; Source: KYTC Snow and Ice Removal Fact Sheet 2016-17

Truck capacity influences how routes are organized. Salt is distributed from the trucks at an average rate of 350 pounds per two-lane mile. The application rate may vary according to road type and size. Trucks often are limited to treating 20-25 miles before returning to a facility for more salt. These facilities are located at central areas within each district and are used as the home base for trucks, where routes begin and end. Mid-route stops at a facility usually take 15-30 minutes. When necessary and when arrangements have been made, trucks may refuel/re-salt at a different facility across county lines.

Salt usage has increased over time. KYTC averaged nearly three times as much salt usage annually in the years after 1994 compared to the years prior (Table 3) - a pivotal year after a major snowstorm shut down roads and even interstates for several days in Louisville and central Kentucky. Public and business outcry over the prolonged road closures led to KYTC investing more resources in both salt and equipment in subsequent years to treat snow covered roads in a more timely manner. Table 4 displays the amounts of deicing substance used during each year in the study. 


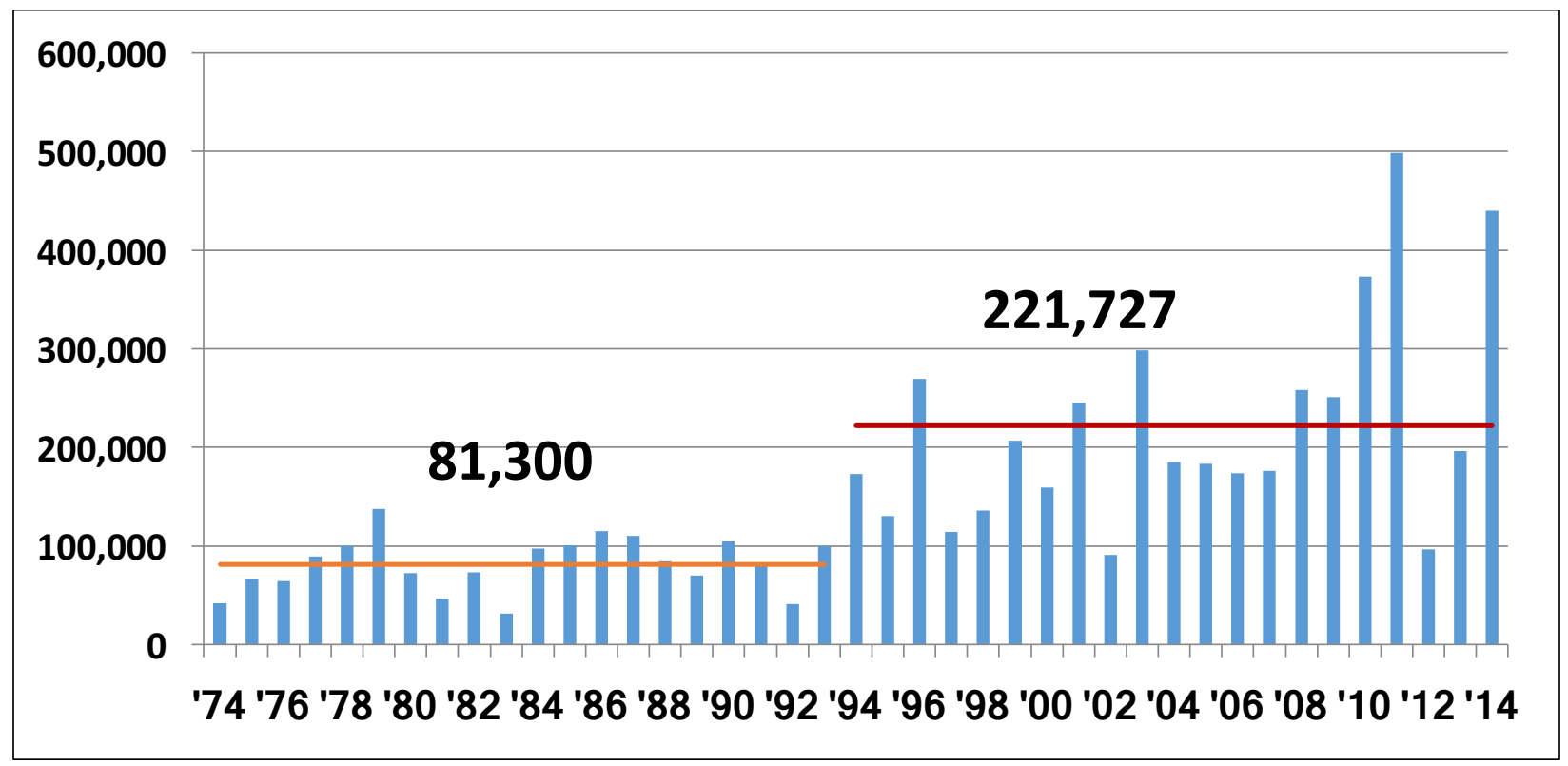

Figure 1 KYTC Salt Usage 1974-2014

Source: KYTC 2014 Snow and Ice Program, presented at the 2014 Section Engineers Meeting

Table 3 Salt, Brine, and Calcium Chloride Usage

\begin{tabular}{|l|l|l|l|l|}
\hline Substance & $\mathbf{2 0 1 3}$ & $\mathbf{2 0 1 4}$ & $\mathbf{2 0 1 5}$ & $\mathbf{2 0 1 6}$ \\
\hline Rock Salt (tons) & 196,100 & 440,100 & 289,111 & 252,800 \\
\hline Brine Solution (gallons) & $2,034,000$ & $1,925,000$ & $2,424,259$ & 913,300 \\
\hline $\begin{array}{l}\text { Calcium Chloride Solution } \\
\text { (gallons) }\end{array}$ & 528,000 & $1,546,000$ & 973,601 & 904,000 \\
\hline
\end{tabular}

Source: KYTC Snow and Ice Removal Fact Sheet 2016-17 


\section{Literature Review}

Researchers began this project by reviewing methods for snowplow routing used nationwide and beyond. Many transportation agencies have attempted to streamline their snow removal process through a variety of methods. Most involved a heuristic approach, often with additional mathematical models. Heuristic refers to the fact that models were interactive, hands-on, and reality-influenced, as this produced the most reliable results.

In 2005, Iowa DOT implemented a web-based Winter Maintenance Decision Support System (WMDSS) that integrates ArcIMC ActiveX Connector with ArcIMS RouteServer Extension and various other web technologies. By integrating geospatial analytical techniques, the existing SRAMS, and SDSS, the tool enhanced the ability to evaluate different snow removal procedures. The system is based on the capacity to manually create, manipulate, and delete routes. It manages resources and provides expert advice to assist with complex decision making such as routing, optimal resource allocation, and monitoring live weather information. Expert knowledge is required to determine the estimated snowplowing time, how many snowplow runs are needed, and total snowplowing time (1).

Quebec, Canada, improved snowplow vehicle routes in 2008, using a combination of methods. The main approach used a model comprised of a multi-commodity network flow structure. In addition, they examined two heuristic solution methods based on mathematical optimization for vehicle routing. Service to each route satisfied a set of operational constraints, real-life restrictions, and a time objective. While the model was useful for small areas, larger networks could not be solved. In addition, route priorities were not addressed (2).

A more recent (2013) study in Alberta, Canada, created a set of routes that would improve safety and mobility for road users while satisfying agency-directed operational constraints. The Ministry of Transportation began by abandoning the network optimization method, which can be limiting for multiple areas with unique conditions and restraints. It instead used a mathematical optimization model based on the Capacitated Arc Routing Problem (CARP) to minimize total travel distance for snowplows. A metaheuristic algorithm was used to solve this model. It was tested in one city and proved sensitive to the depot location and number of routes (3).

FHWA performed a study in 2011 to provide state DOTs with the knowledge and tools to address road weather conditions in three ways: public advisory, traffic control, and snow-removal treatment. Researchers analyzed traffic density, speed, and capacity; they also examined how precipitation affects those numbers. For snowplow operations, routing could be manipulated to treat heavily trafficked roads first. This resulted in better decision making by DOTs and motorists, and improved reliability, safety, and mobility on the roadway system during adverse weather (4).

In 2011, Missouri's DOT (MoDOT) developed procedures for snow removal operations involving fleet location, route decision, and material selection. The development was based on a heuristic approach. Optimizing truck allocation and revising route decision policies let MoDOT close some maintenance buildings without sacrificing efficiency or high levels of service (5).

A 2013 study approached the snowplow problem from two directions: routing and application rate of salt/chemicals. A mixed integer linear problem (MILP) was used to minimize the total operation time of all snowplows and reduce the longest individual truck time. The methods developed were applied to an empirical case study and computational results indicated that it solves the problem efficiently. This study is being further developed to create a software that will assist in planning routes (6). 
Vermont Agency of Transportation (VTrans) developed storm-specific routes for its snowplows in 2013 to improve service efficiency while minimizing labor hours and fuel. The project optimized the service areas for each maintenance garage based on the travel time between each garage and the surrounding road network. Vehicles were reassigned to the garages based on this method and routed according to the combined service time/fuel consumption metric. The model performance varied depending on the input parameters, but provided information that will influence future snowplow-related operations (7).

Also in 2013, the city of Centennial, Colorado, revised snowplow allocation based on research showing a significant variability among trucks both in miles traveled and in coverage of priority level roads. As part of the reallocation, routes were divided into two priority levels. Optimization was based on time to complete the route and involved clearing all Priority 1 roads before starting on Priority 2 roads. Routes were developed using a mathematical version of the "postman problem", in which deliveries are made via an optimized route. The reallocation reduced miles traveled, decreased fuel costs, cut labor hours, and lowered $\mathrm{CO}_{2}$ emissions (8).

Most efforts to improve and optimize snowplow routing use a heuristic interactive approach, often with supplemental mathematical models. Several agencies have experienced improved snowplow operations after implementing their chosen method; others undertook computational experiments but stopped short of implementation for various reasons. In addition, most of this methodology was relatively old, of questionable accuracy, or not available to third parties. There is not a precedent for implementing a GISbased method. The lack of promising research on other methods combined with KTC researchers' extensive experience with GIS prompted the development and evaluation of an entirely new GIS-based method for routing snowplows. 


\section{Methodology}

KTC researchers met with district officials to evaluate the current system for routing snowplows. They articulated the specific needs for new methods and suggested that KTC focus on optimizing routes for a typical snow event, which is defined as a 1-inch snowfall. With this goal in mind, KTC defined work parameters, evaluated the current routes as a control, and created new routes using the Network Analyst feature of ArcGIS.

\section{Control Routes}

Snowfall in Kentucky typically occurs in two- or three-day bursts. For this reason, snow removal is treated as an emergency rather than a maintenance activity. Each district has a snow and ice book that outlines the currently used control routes. Researchers used these books to verify route prioritization and evaluate control routes. In some cases, districts had additional digital files they shared with KTC. A combination of books, digital files, and other notes were used to compile current routes in Network Analyst. Typical routes are 20-25 miles. Time required for these routes was calculated through Network Analyst and through total time tallied for all routes. Current route times are compared with new route times to serve as the baseline for analysis.

\section{New Routes}

New routes were created for each district in Kentucky with the goal of improving the efficiency and simplicity of truck routes. Throughout the process, researchers adhered to Level of Service figures and other expectations for each roadway. For routing analysis purposes, it was assumed that a truck uses $80 \%$ of its capacity before returning to the facility. Each truck was limited to one repeatable route. All other conditions adhered to the parameters originally set up in Network Analyst according to KYTC expectations.

Researchers developed new routing solutions for each county. These routes were then combined to show all the county-level routes within a district. Initially, KYTC officials discouraged inter-county travel because organization over such a large area is difficult. However, this thinking was revised; those details are discussed later in this paper. KYTC officials told researchers that it was not imperative to treat all A routes before $\mathrm{B}$ or $\mathrm{C}$ routes; however, this was an ancillary goal of the analysis since optimization is likely to correlate with route prioritization.

\section{Vehicle Routing Problem}

All routes, including the existing control routes and the newly created routes, were developed using Esri's Network Analyst. Routes were set up as a Vehicle Routing Problem (VRP), which finds the best routes for a fleet of vehicles to service many orders or deliveries of a product. In this case, it allowed researchers to treat salt as a product being delivered to specific sites along roadways. VRP is a generalization of the Traveling Salesman Problem, the goal of which is to find the optimal solution for a fleet of vehicles to service a set of orders. In the context of this research project, the set of orders refers to deliveries of salt on the roadways. This process was identified as the most suitable to optimize snow and ice clearance routes. The road network dataset was prepared to enable the performance of several difference types of analysis using the ArcGIS Network Analyst extension. Preparation of the network and the VRP are discussed in the following sections. 


\section{Setting Up the Network}

\section{Route Overlay}

Researchers started with the centerline roadway network (Allrds_m) from KYTC and an intersection database (9), but the data required some manipulation before it could be used for this project. The road layer was overlaid with the required roadway attributes: number of lanes, traffic volume, one-way/two-way, route type, speed limit. Using the intersect tool, points were created at all intersections on the new layer. This created single point features from multipoint features. The split tool was used to dissolve road layers at intersection points so that they could be treated as individual entities during the VRP analysis. This gave a complete map of all roads and intersections requiring treatment.

\section{Directionality for One Way and Divided Highways}

To correctly set up a network, flows and directionality need to be closely accounted for. The issue of directionality is most salient for one-way streets, divided highways, turning lanes, entrance/exit ramps, and roundabouts. Network Analyst accounts for directionality through the creation of a One-Way Restriction Attribute in the road layer. Each line segment in a road layer has an inherent directionality to it, defined by the segment's endpoints. One endpoint is the F (from) endpoint; the other is the T (to) endpoint. Directionality can be defined for one-way streets by creating an attribute field ("ONEWAY") in the road layer defined as:

- "FT" if the directionality begins at the F endpoint and moves toward the T endpoint

- "TF" if the directionality begins as the T endpoint and moves toward the F endpoint

- The field can be left blank if directionality on the line segment is both ways

Assigning road network directionality is a multi-step process. The workflow used to accomplish this is diagrammed in Figure 2. 


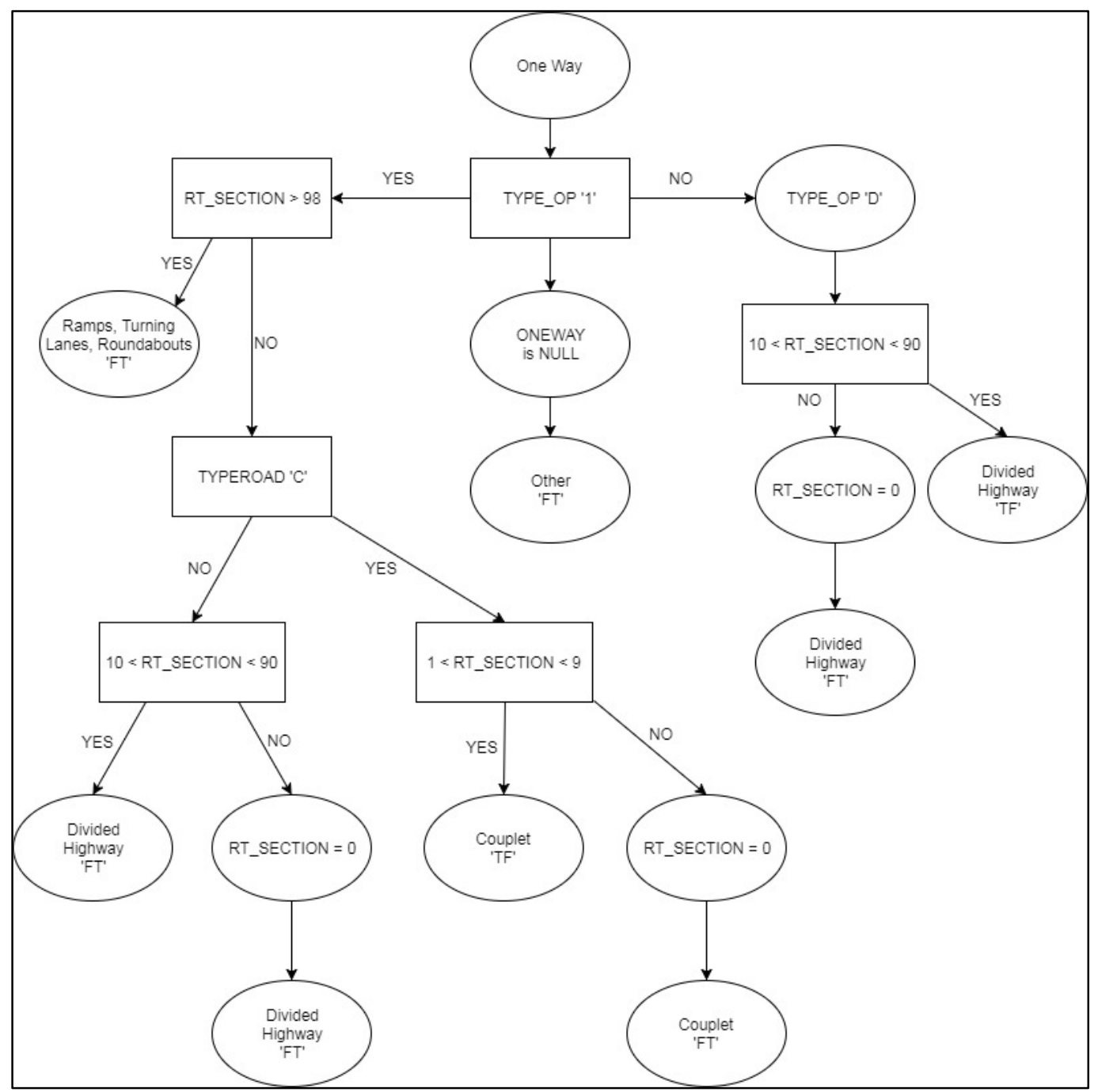

Figure 2 Decision Logic for Network Directionality

\section{Simplifying the Network}

The Network Analyst solver functionality works as a complex algorithm that considers all the possible outcomes to determine the lowest cost solution. For the algorithm to work efficiently, it is imperative to reduce the complexity of the network as much as possible. The program operates more effectively when the network has fewer variables to consider.

Using ArcGIS and the third-party extension ET GeoWizards, a series of geoprocessing steps were performed to reduce the number of line segments representing the road network. Geoprocessing created unified road segments between every intersection and at county lines. The following steps were performed:

- Use the ET GeoWizards tool Export Nodes to identify and export as points the beginning and ending nodes of all the lines in the road layer.

- Use the Unsplit tool to dissolve the road layer.

○ Dissolve on the attribute fields: 
- RT_UNIQUE: this is the unique route identifier assigned by KYTC to every road

- SNIC_KTC: this refers to the KYTC Snow and Ice priority route system, where roads are assigned to priority $\mathrm{A}, \mathrm{B}$, and $\mathrm{C}$ levels

- SNIC_Lanes: this refers to the number of lanes in the road. Because turning lanes were excluded from this analysis, the original Lanes field was rounded down to the nearest even number to determine the number of SNIC_Lanes

- OneWay: refers to whether the line segment is directionally one-way

- SNIC_Speed: refers to the assigned speed of the snow plow trucks. For two-lane rural routes and other routes where the speed limit is less than $45 \mathrm{mph}$, the SNIC_Speed is $15 \mathrm{mph}$. For larger roads where the speed limit is $45 \mathrm{mph}$ or above, the SNIC_Speed is $30 \mathrm{mph}$.

- Two other fields were kept but not dissolved on:

- Start Milepoint: the minimum value is kept

- End Milepoint: the maximum value is kept

- Once the layer has been dissolved, it must be split at the intersections for Network Analyst to understand the connectivity of the network. With the newly unsplit layer, the Intersections tool was used to create a point at every intersection of the lines in the layer. This generated more points than needed, as intersection points created were not topologically correct (for example, when one road overpasses another without an intersection)

- To identify what intersection points to preserve, the Select By Location identified which intersection points also intersect with the nodes created in the first step of this process. Nodes that do intersect are exported as a new shapefile.

- The Split Line at Point tool split the dissolved road layer with the newly intersected points. This resulted in a road layer that was less complex and topologically correct.

Completing these steps reduced the number of road segments from 98,721 to 34,174 statewide. This reduction led to a corresponding improvement in the ability of the Network Analyst solver to operate efficiently and effectively.

\section{Multiple Lanes}

For roads that have more than two lanes (one in each direction), it is necessary to devise a scheme within Network Analyst whereby the solver understands that multiple passes by one truck or multiple trucks are needed to clear multiple lanes. To address this problem, multiple parallel lines were created for multi-lane roads and added to the network. This problem was solved in several steps.

First, researchers identified roads with multiple lanes. The Highway Information System (HIS) database provides this information. The meaning of the number depends upon the road type - a divided highway, undivided highway, or couplet. The following figure illustrates the steps used to identify segments with multiple lanes for each road type. 


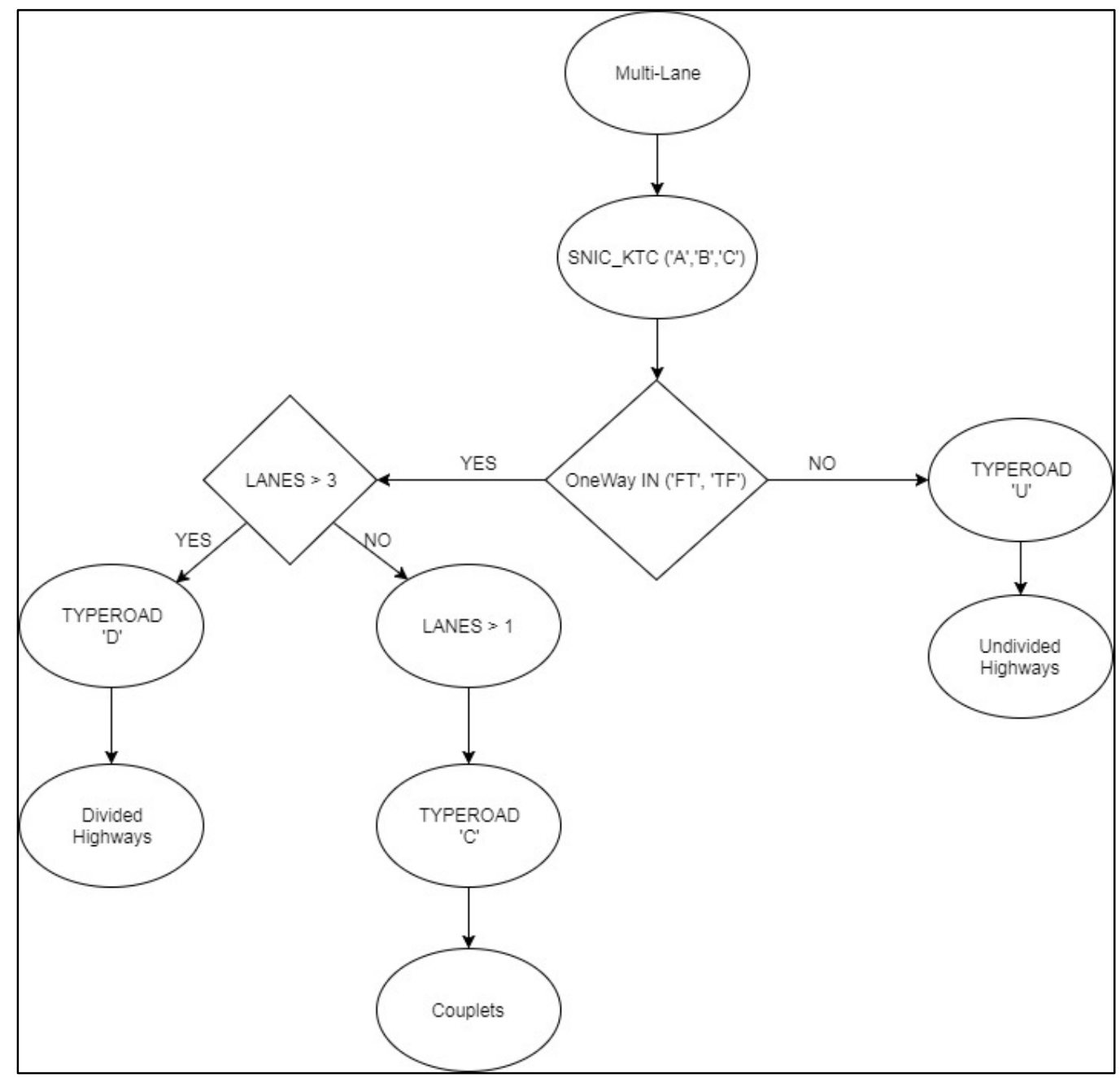

Figure 3 Decision Logic for Lane Assignment

- After creating and exporting the parallel lanes, they were combined in a single shapefile representing all parallel lanes in the network.

Additional steps were needed before they were joined to the original network. As the lines were parallel, the endpoints of each line were snapped to intersections to preserve the correct network topology. For the parallel lines shapefile, add a Field entitled "Vertices"

- Use Field Calculator for "Vertices"

- Change the Parser to Python

In the main expression box, VxCount = ! shape!.pointcount

This routine calculates the number of vertices in every line segment. With this field, line segments with fewer than three vertices were selected and exported to a layer. For these selected line segments, more vertices can be added by using the ArcGIS tool Densify. The Densify tool adds vertices at assigned intervals. Determining appropriate spacing for vertices requires some thought. The length must be less than the shortest line segment in the layer, otherwise that line segment will not receive any new vertices. On the other hand, segment length may vary considerably. If the shortest line segment is 30 feet, new vertices could be added every 15 feet. However, for a segment that is 10 miles long adding new vertices 
every 15 feet would introduce unnecessary and burdensome complexity to the network. To address this problem, the line segments were divided into 'tiers' based on their lengths. For each tier, the Densify tool was used to add new vertices at a length appropriate for the tier.

Lastly, endpoints of parallel lines were snapped to intersections in the original road network shapefile. The tool used for this was the ET GeoWizards tool Global Snap Polylines; line endpoints were snapped to intersection points using a tolerance of 10 feet. Some of the parallel lines on roads with many lanes were more than 10 feet away. After completing the initial snap, researchers identified which lines had not snapped yet. For these, the Global Snap Polylines tool was run with a tolerance of 20 feet. The tolerance was increased until all line segments were correctly snapped.

After completing these steps, the parallel lines were joined to the original Road Network shapefile using the Merge tool. The resulting road network shapefile was used to create the network for Network Analyst.

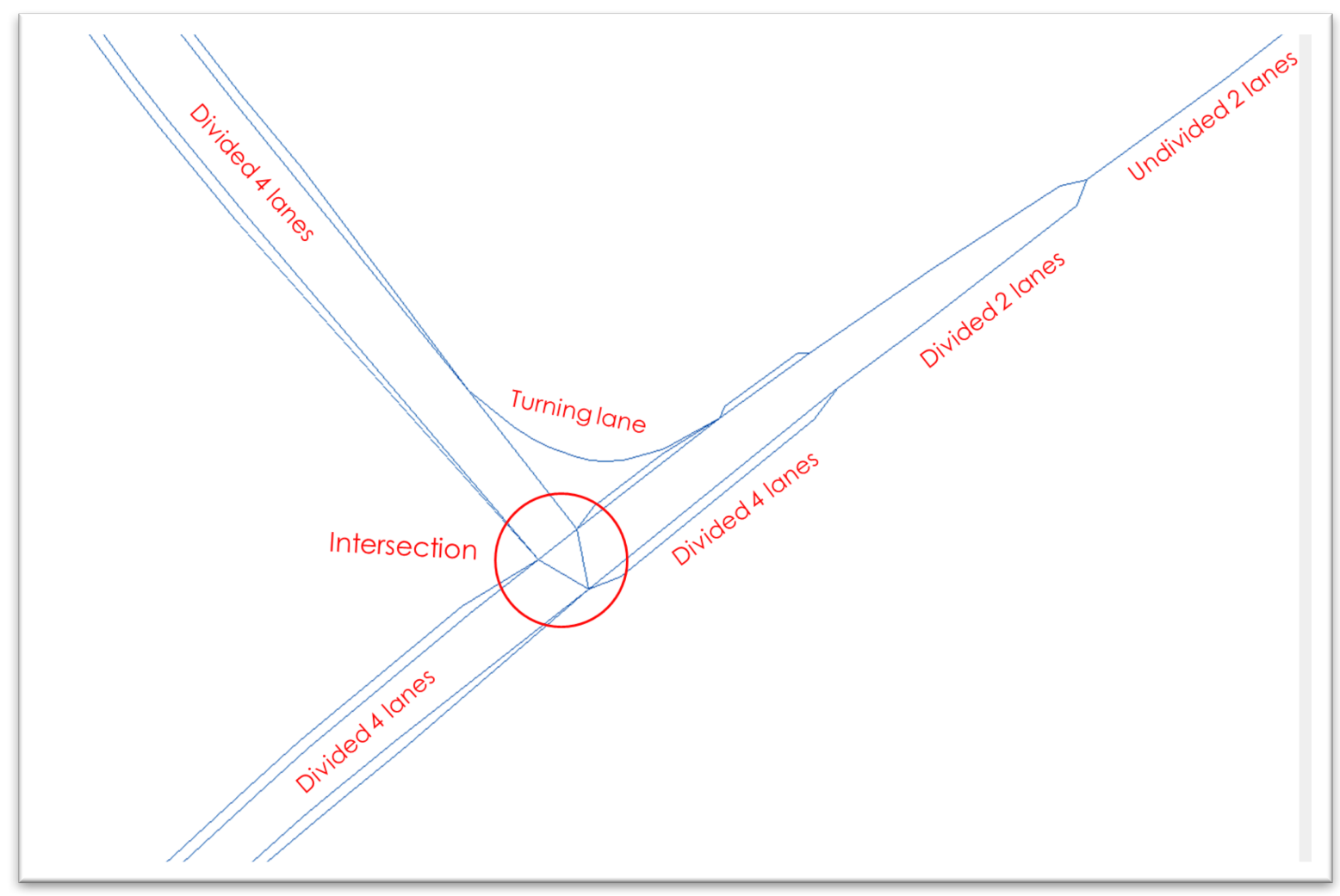

Figure 4 Setting up Roadway as Multiple Lanes

For divided highways, data from the mainline counterpart were used. A VRP parameter, global turns, allows non-restricted movement at any edge or intersection, indicative of how snowplows may travel.

\section{Building the Network}

When building the Network Dataset, the following settings were applied:

- Feature classes included: Roads

- Model turns - Yes; set to Global Turns

○ Connectivity Policy: End Point

- No Elevation Fields included

- Attributes

○ Feet 


\section{- Miles \\ - Minutes \\ - OneWay \\ - No Travel Modes \\ - No Driving Directions}




\section{Vehicle Routing Problem}

The road network dataset was prepared to enable the performance of several different types of analysis using the ArcGIS Network Analyst extension. To optimize snow and ice clearance routes, the VRP was identified as the most suitable. VRP is a generalization of the Traveling Salesman Problem, the goal of which is to find the optimal solution for a fleet of vehicles to service a set of orders. In the context of this research project, the set of orders referred to deliveries of salt on the roadways.

To account for salt deliveries, the road segments were converted to delivery points that included fields indicating the amount of salt needed for application on each road segment. To create delivery points, midpoints were created for all the road segments with ET Geowizards. The midpoints were offset to the right of the driving direction (Figure 5). Points represent salt deliveries. In addition, constraints were set that limited deliveries to the right side of the vehicle.
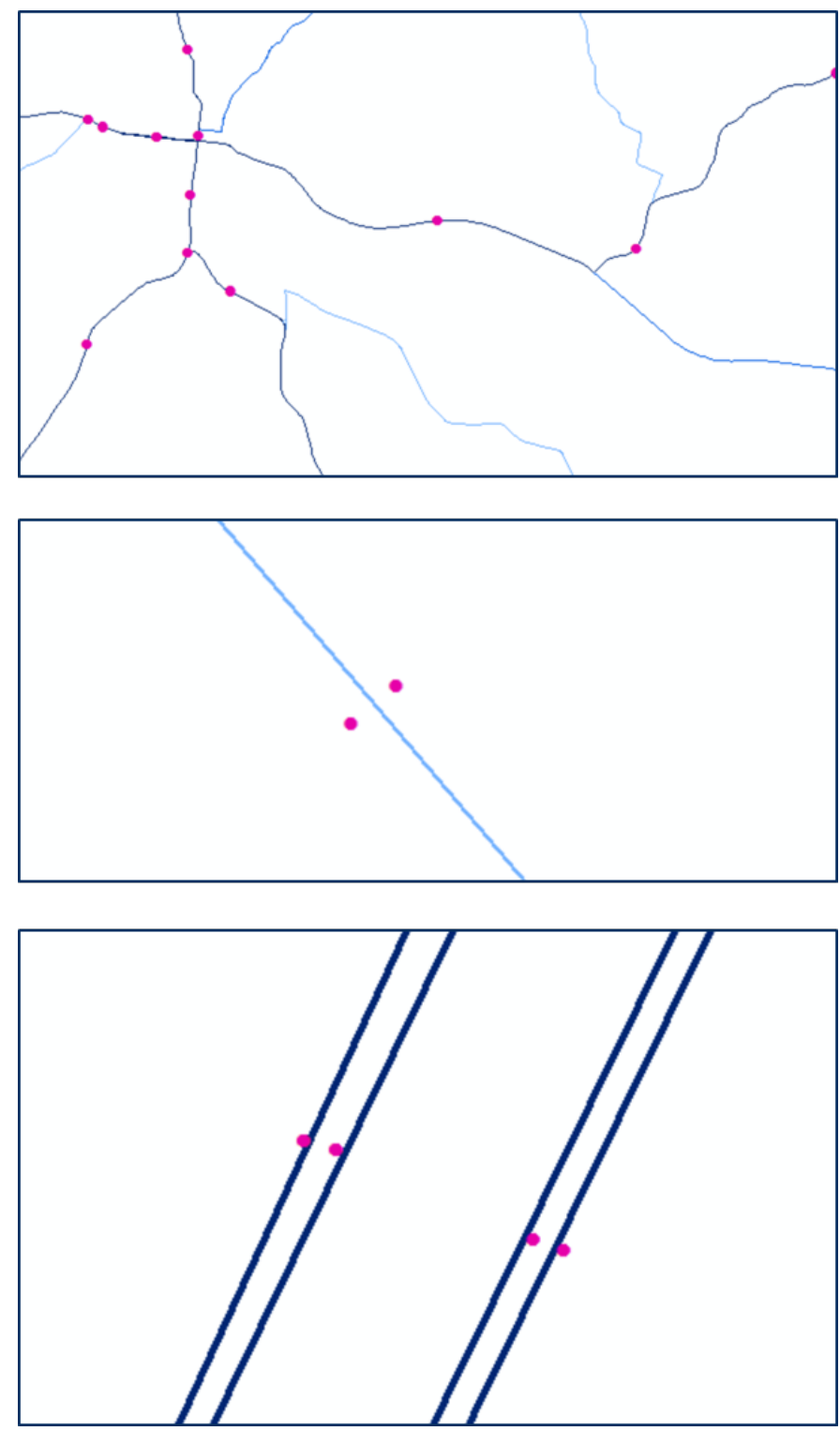

Figure 5 "Delivery" Points for Salt on Either Side of Roadway 
These geometric and data-based parameters ensured that snowplows travelled in the correct direction and that a single truck did not cover two points of delivery in the same pass. An additional factor specified the length of the road segment as a delivery quantity. As a truck treats a road, the length factor ensured that no truck exceeded its capacity in one trip.

To create the points, the ET GeoWizards tool "Points Along Polylines" was used. For each road segment, one point was created at the midpoint of the road segment and offset from the line by two feet. For lines representing two-way roads, a point was created and offset two feet from the line on both sides. For lines where ONEWAY = 'FT', a midpoint was created and offset two feet to the right. For lines where ONEWAY = 'TF', a midpoint was created and offset two feet to the left. Points were created for all road segments in the SNIC priority route system except for turning lanes. Turning lanes are typically treated at the discretion of the snowplow drivers, depending on time and material availability.

An average salt distribution rate must be set to determine the amount of salt needed. For this project, an average salt distribution rate of 350 pounds of per lane mile was chosen. Using this number, rate calculations were made to estimate the amount of salt needed for each road segment based on segment length. For the VRP, this field was labeled "DeliveryQuantities."

The problem of time windows for salt delivery was also addressed in the salt delivery points layer. Time windows refers to the SNIC priority system, where routes are designated as A, B, or C routes. For each priority level, trucks are assigned to treat the routes at specified intervals: A routes are every two hours, B routes are every four hours, $\mathrm{C}$ routes are every eight hours. Additionally, interstates and parkways require treatment once per hour. Time windows were used to designate within their specified interval when a truck needs to deliver salt to each point. This research was designed to model truck movements during a typical winter storm, so a typical 8-hour shift was assumed for truck operators. Within this time frame interstates and parkways require eight treatments (once every hour), A routes four treatments (every two hours), B routes two treatments (every four hours), and $\mathrm{C}$ routes receive one treatment. To account for multiple passes, salt delivery points were duplicated based on the number of passes needed. Within the attribute table, multiple time window fields were created to account for duplicate points. Table 4 displays an example of how this was created.

Table 4 Time Parameters for Route Priority Level

\begin{tabular}{|l|l|l|l|l|l|l|l|l|}
\hline $\begin{array}{l}\text { SNIC } \\
\text { Priority }\end{array}$ & $\begin{array}{l}\text { Time } \\
\text { Window } \\
\text { Start 1 }\end{array}$ & $\begin{array}{l}\text { Time } \\
\text { Window } \\
\text { End 1 }\end{array}$ & $\begin{array}{l}\text { Time } \\
\text { Window } \\
\text { Start 2 }\end{array}$ & $\begin{array}{l}\text { Time } \\
\text { Window } \\
\text { End 2 }\end{array}$ & $\begin{array}{l}\text { Time } \\
\text { Window } \\
\text { Start 3 }\end{array}$ & $\begin{array}{l}\text { Time } \\
\text { Window } \\
\text { End 3 }\end{array}$ & $\begin{array}{l}\text { Time } \\
\text { Window } \\
\text { Start 4 }\end{array}$ & $\begin{array}{l}\text { Time } \\
\text { Window } \\
\text { End 4 }\end{array}$ \\
\hline A & $8: 00 \mathrm{AM}$ & $10: 00$ & $10: 01 \mathrm{AM}$ & $12: 00 \mathrm{PM}$ & $12: 01 \mathrm{PM}$ & $2: 00 \mathrm{PM}$ & $2: 01 \mathrm{PM}$ & $4: 00 \mathrm{PM}$ \\
\hline $\mathrm{B}$ & $8: 00 \mathrm{AM}$ & $12: 00$ & $12: 01$ & $4: 00 \mathrm{PM}$ & & & & \\
\hline $\mathrm{C}$ & $8: 00 \mathrm{AM}$ & $4: 00 \mathrm{PM}$ & & & & & & \\
\hline
\end{tabular}

Several other fields were added to the salt delivery points to prepare for the VRP. A field titled "CurbApproach" was created, and the Field Calculator was used to populate all entries with the number 1. This indicates to the VRP solver that salt deliveries are only allowed on the right side of the vehicle. Thus, on two-way roads with points on either side, the truck must traverse the road in both directions to plow and deliver salt to both sides.

A final field added was titled SpecialtyNames. Creating this field enabled greater customization and control over how the trucks solve the Vehicle Routing Problem. The SpecialtyNames field is simply an expression of the SNIC priority, where each point in the field is calculated as either A, B, C, or I, where I represents interstates and parkways. 


\section{Setting up the VRP}

VRP Parameters:

- Orders: In the context of the VRP, orders refer to the deliveries that need to be made by the fleet of trucks. Orders data are sorted into fields for quantities, service time, curb approach (indicates from which side of a truck the delivery can be made), and delivery time windows

$\circ$ Orders is defined as the amount of salt that must be delivered to each road segment.

- Depot

- Specialties

- $\quad$ Routes

- Route Renewals

- VRP Properties

- Time and Distance Attributes

○ U-Turns set to "Allowed only at intersections and dead ends"

Table 5 summarizes the VRP setup. VRP parameters are listed on the left and the SNIC parameter is on the right.

Table 5 Vehicle Routing Problem Setup

\begin{tabular}{|l|l|}
\hline VRP Parameter & SNIC Parameter \\
\hline Orders & Salt delivery points (i.e., midpoint of road segment) \\
\hline Depot & County maintenance facility containing equipment and salt \\
\hline Specialties & Restricts certain types of trucks to certain types of routes \\
\hline Routes & Number and type of truck available for the county \\
\hline
\end{tabular}




\section{Results}

\section{First Iteration}

To determine the performance of the new optimized routes, they were compared with control routes (i.e., routes currently used for the KYTC SNIC program). Differences in treatment times were quantified in minutes and percent improvement. Table 6 summarizes these differences for each county in District 7.

Table 6 Minutes to Treat All Routes per County (District 7)

\begin{tabular}{|c|c|c|c|c|}
\hline County & Current Routes & Modeled Routes & Difference & \% Improvement \\
\hline Anderson & 1,358 & 1,296 & 62 & $4.6 \%$ \\
\hline Bourbon & 1,529 & 1,287 & 242 & $15.8 \%$ \\
\hline Boyle & 926 & 892 & 34 & $3.7 \%$ \\
\hline Clark & 2,651 & 2,394 & 257 & $9.7 \%$ \\
\hline Fayette* & 2,004 & 1,376 & 628 & $31.3 \%$ \\
\hline Garrard & 997 & 961 & 36 & $3.6 \%$ \\
\hline Jessamine & 1,050 & 925 & 125 & $11.9 \%$ \\
\hline Madison* & 957 & 824 & 133 & $13.9 \%$ \\
\hline Mercer & 1,114 & 1,114 & 0 & $0.0 \%$ \\
\hline Montgomery & 1,210 & 1,210 & 0 & $0.0 \%$ \\
\hline Scott* & 3,177 & 3,177 & 0 & $0.0 \%$ \\
\hline Woodford & 1,089 & 1,089 & 0 & $0.0 \%$ \\
\hline TOTAL & $\mathbf{1 8 , 0 6 2}$ & $\mathbf{1 6 , 5 4 5}$ & $\mathbf{1 , 5 1 7}$ & $\mathbf{8 . 4 \%}$ \\
\hline
\end{tabular}

*Does not include interstate and parkway routes

The initial results held promise, with an overall $8.4 \%$ improvement across the district in treatment time. Fayette County stood to benefit the most, with a $31.3 \%$ reduction in treatment time. Four counties Mercer, Montgomery, Scott, and Woodford - showed no potential for improvement.

In some cases, the model demonstrated that trucks could not complete their routes as described within the time window. However, KYTC officials did not view this as a major problem for most routes. Occasional violation times are acceptable. If violation times were consistently high, it would indicate a need for more trucks. KYTC officials did, however, specify violation times of zero for interstates, as it is critical for interstates to receive treatment in a timely manner.

Closer examination of the routes by KYTC personnel revealed problems with the routes produced in the initial run. Most significantly, the routes produced by the model were overly complicated and not feasible if attempted. In many cases, the model would send multiple trucks to treat the same stretch of roadway at different times during the day. For example, the model might assign an A route to be treated by one truck the first pass of the, day, while on the second, third, and fourth pass, different trucks would be assigned to the route. Meanwhile the first truck that treated the route was then treating a new A route. This meant that 
trucks would travel all over a county at different times during the day, and all the trucks would have to coordinate precisely to achieve proper timing. This would present multiple problems for KYTC personnel. Figure 6 illustrates the routes by priority in Anderson County.

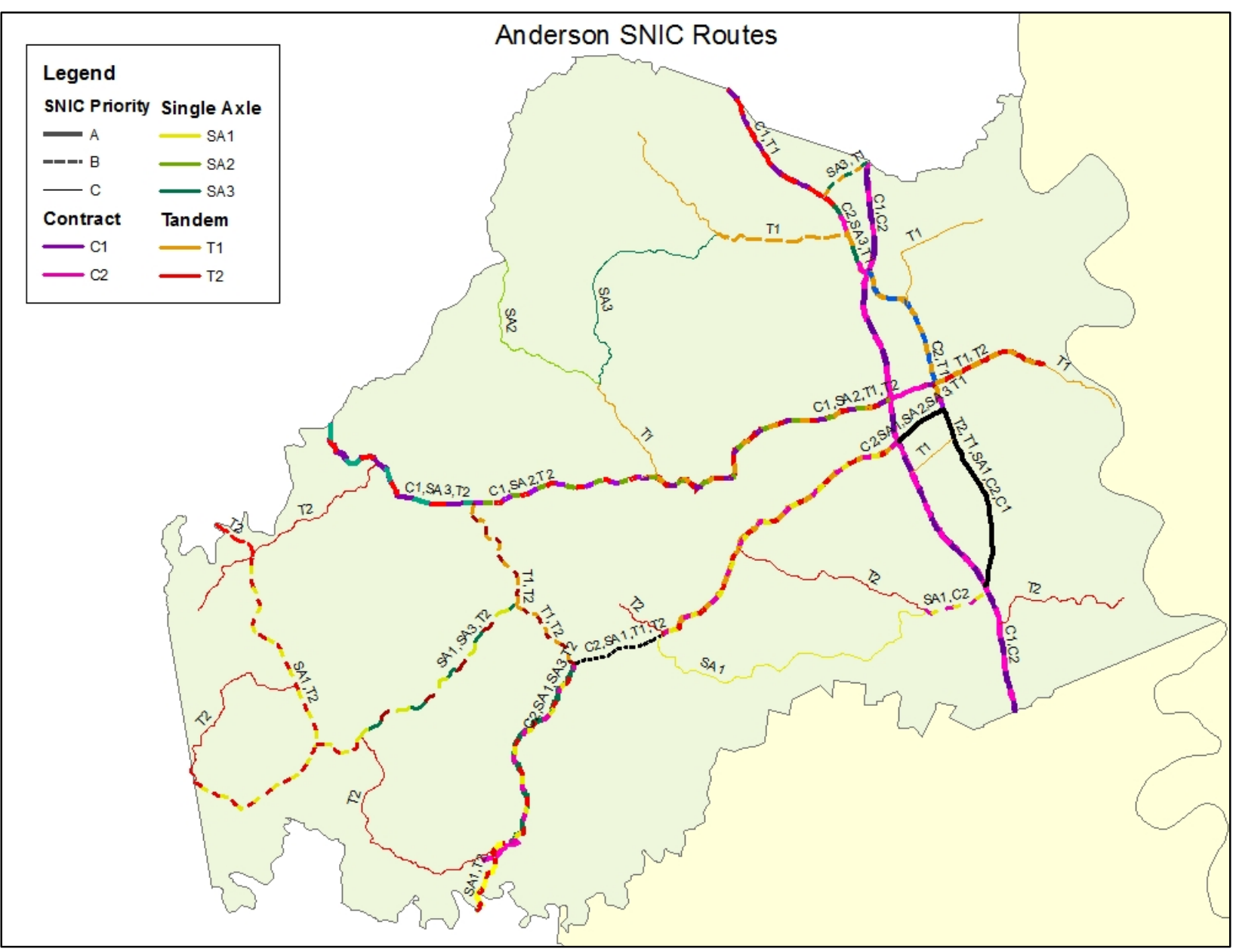

Figure 6 Example of First Iteration of Route Optimization (Anderson County)

A second problem with the results was that the complexity of the routes would limit the ability of truck drivers to become familiar with the routes they run. On this point, the participation of truck operators on the KYTC Study Advisory Committee was critical. Drivers stated that their familiarity with the routes was important for promoting safety and SNIC effectiveness. They described the importance of knowing even minute details roads, because they are covered in snow - and may not be visible - during operations. Knowing the locations of culverts, guardrails, mailboxes, close-by trees, or other obstacles is critical as they can impact the effectiveness of snow and ice removal. As a result, overly complex routes were met with hesitation from snowplow operators.

A third problem with the routes was that it was unclear whether model's results were mathematically optimized. There seemed to be some discrepancy with the Network Analyst VRP solving algorithm in that it began to fail when too many variables were added. The discrepancy between the model's results and a mathematically optimized solution resulted when too many variables were added to the Network Analyst VRP solving algorithm. Close inspection of the model results revealed instances of routes that were neither optimized nor optimal. To address these problems, further investigation of the problems with the VRP solver was set aside so researchers could adjust the methodology. 


\section{Modifications}

To address the problems found with the results from the model's first iteration, the methodology was revised considerably. This called for redefining the project's research goals. In other words, rather than searching for the mathematically optimized solution to the routing problem, the goal became to identify an optimal and realistically applicable solution. This meant no longer viewing the Network Analyst VRP as the ultimate producer of the solution, repositioning it instead as a tool to guide development of a proper solution. This required more hands-on scrutiny of each county and each route, and an understanding of how their interconnections affect the ability of trucks to treat each route on schedule.

Most significantly, the Study Advisory Committee expressed a preference for truck routes that centered on specific $\mathrm{A}$ routes and then built outward to address the $\mathrm{B}$ and $\mathrm{C}$ routes. This became known as the route tree solution. Where possible, each truck route for a county began with a center trunk (A route) and branched out to treat the adjoining branches (B and C routes). KYTC truck operators preferred this approach, as it will allow them to quickly gain familiarity with their routes. A secondary benefit of a route tree system is that is better suited for adaptation in a real-world setting, when storms differ from what is expected. There is significant variability from storm to storm in snow intensity, temperature, wind speed, duration, and extent of the area impacted. Trucks have greater flexibility to treat roads as needed when they are assigned to specific trunks and branches on the route tree. For example, during a heavy snowstorm when A routes warrant greater attention, trucks can easily continue to treat their assigned A routes before proceeding to routes with lower priority.

\section{Final Results}

Ultimately, the Study Advisory Committee settled on the revised methodology to pursue route modeling. The modified methodology was applied to four counties: Clark County and Montgomery County in District 7, and Grant County and Pendleton County in District 6. These county pairs were selected by the Study Advisory Committee in hope that combining these counties together in the analysis would produce further optimizations.

For this exercise, Network Analyst was used to identify, tabulate, and monitor time required and salt usage as the routes were compiled. While Network Analyst did not ultimately generate the results, it was useful for determining which combinations of $\mathrm{A}, \mathrm{B}$, and $\mathrm{C}$ routes were appropriate for each truck route.

A different metric was used to gauge the success of the second round of modeling. Instead of tracking the total time required to treat all the routes on schedule in a county, the team tracked the total number of trucks needed per county to treat all the routes. This was a more useful and applicable metric due to the KYTC Study Advisory Committee's stated preference for eliminating contract truck routes where possible. To this end, the model attempted to maximize the number of roadway miles treated by state trucks before including contract trucks in the modeling scheme.

The revised modeling indicated that KYTC can treat all routes on schedule and use fewer trucks in the process. Because fewer contract trucks are needed, KYTC can potentially realize significant cost savings. For Grant and Pendleton Counties (District 6) the model demonstrated the potential to eliminate six contract trucks, resulting in a cost savings of $\$ 25,000$ per truck per year. Similar results were found for Clark and Montgomery Counties in District 7, where route optimization suggested that three contract trucks could be eliminated, with a similar cost savings of $\$ 25,000$ per truck per year. Accounting for just these four counties, KYTC could save up to $\$ 225,000$ per year.

By combining counties, the model also found the potential for route optimization by letting trucks cross county lines. The model suggested a new route along US 60 between Winchester (Clark County) and Mt. Sterling (Montgomery County). This type of intercounty route represents a new approach for KYTC, which has typically operated the SNIC program within single counties. Figures 7-10 present the model results. 


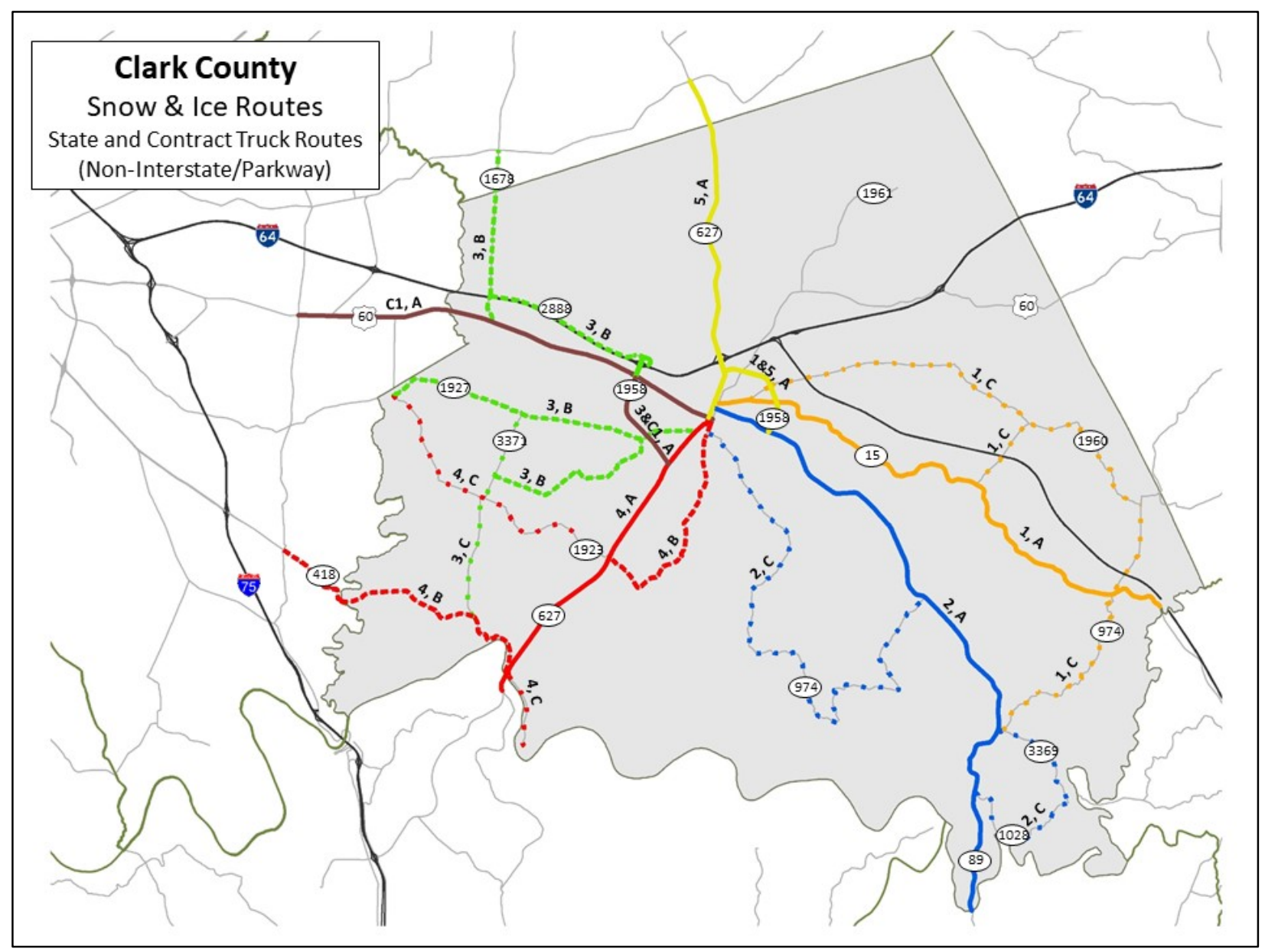

Figure 7 Clark County Optimized Routes 


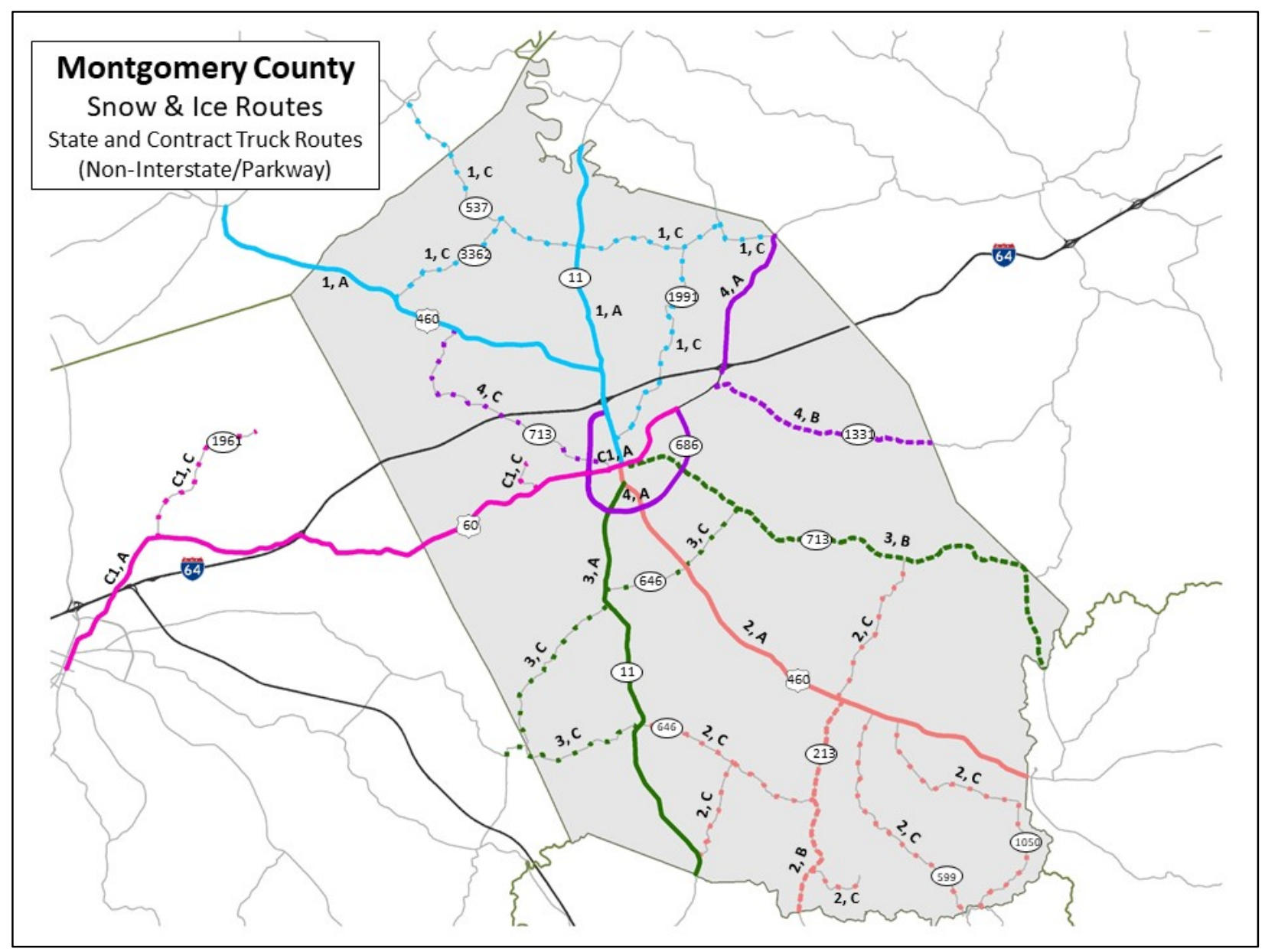

Figure 8 Montgomery County Optimized Routes 


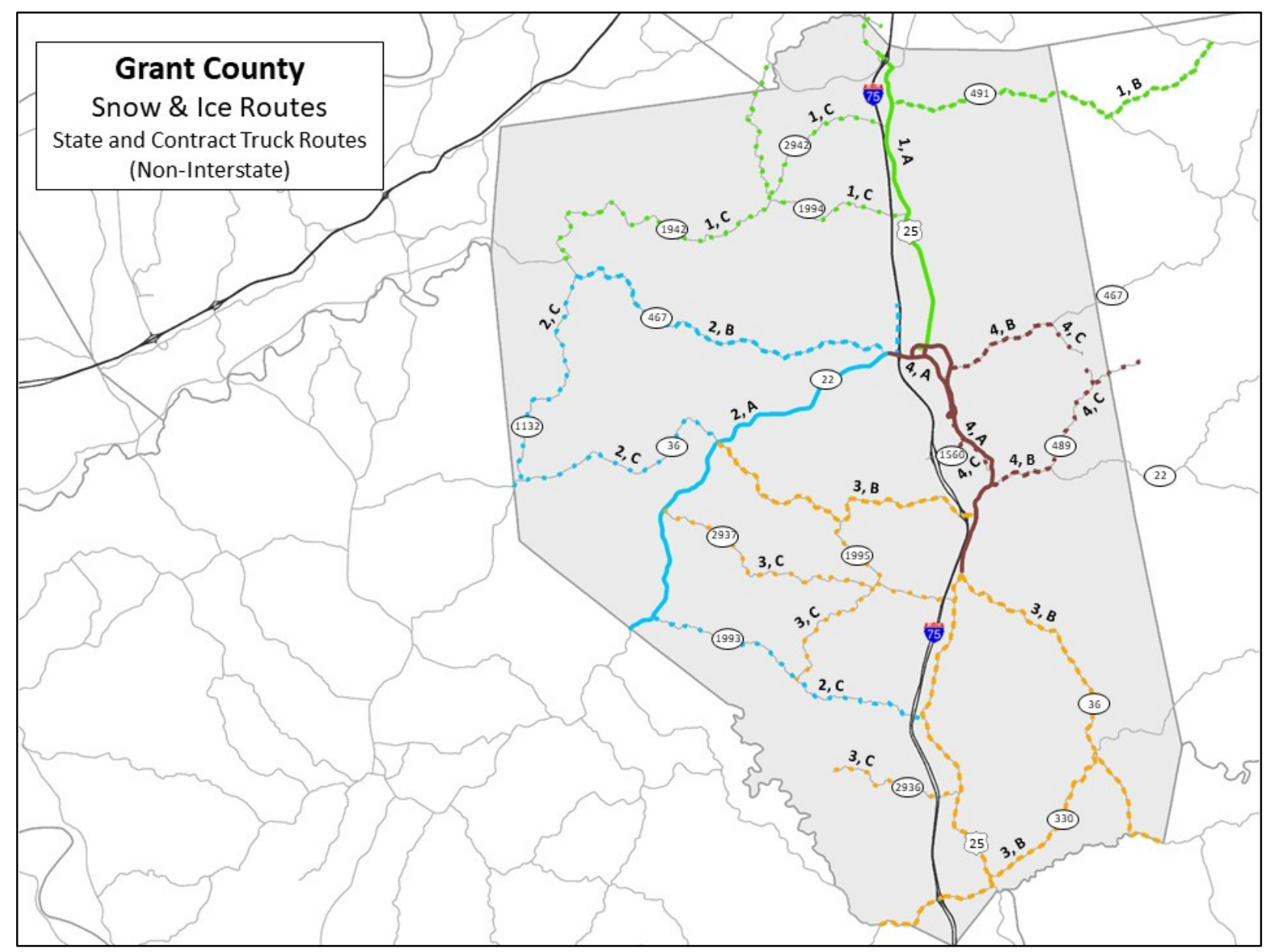

Figure 9 Grant County Optimized Routes 


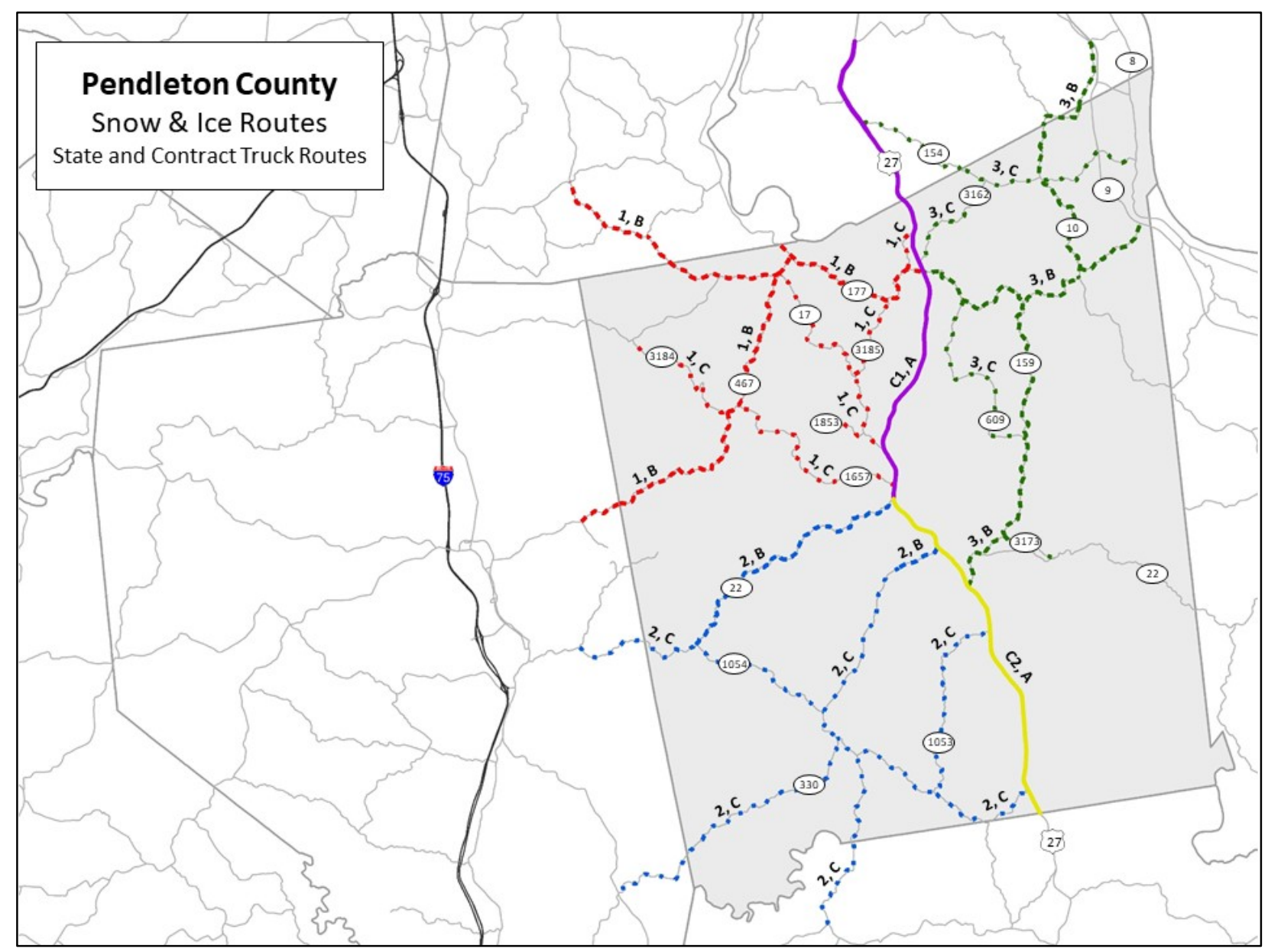

Figure 10 Pendleton County Optimized Routes 


\section{Conclusions}

Throughout this project's development, KTC researchers adhered to KYTC expectations and maintained familiarity with the SNIC process to maximize improvements. In doing so, researchers presented a successful method to optimize snowplow routing. As the results of this project are expanded throughout the state, KYTC personnel should be aware of those lessons learned throughout the project. The following is a summary of what could benefit practitioners employing a similar snowplow route optimization.

- Taking advantage of local knowledge when developing snowplow routes is critical. Route analysts must know what a district's current practices are, its goals, and what kinds of routes drivers are and are not willing to do. Talking with district officials and snowplow drivers was critical for this project and helped researchers build a model that was responsive to the needs of district officials and drivers.

- In replicating the methodology described in this report, care should be taken to simplify the network when setting up the data. Using each road's midpoint as the delivery point, rather than establishing points every 100 feet, produced a less complex network that vastly improved solver performance. Not only were the routes more straightforward, but this methodology significantly reduced the solver's run time - from hours to seconds. A simplified network sacrifices some roadway attributes, however, researchers and officials will need to ensure that important aspects are accounted for.

- Used alone, the VRP's effectiveness is limited. Without user input, the VRP returned many routes that were clearly not the most efficient option. However, by varying constraints and trying multiple iterations, researchers developed better routes. Therefore, a combination of VRP and hands-on manipulation appears to be the best practice for developing snowplow routes.

- The network dataset should be constantly monitored and checked for quality. Even the smallest network connectivity error can lead to major problems. During this process, researchers encountered the following problems: broken connections between divided highways, incomplete lines approaching intersections, and geometric anomalies. All issues were fixed, but finding and correcting them can be timeconsuming. The VRP solution depends heavily on correct data, so ensuring accuracy is very important.

- Altering constraints slightly can produce vastly different results. Some of the constraints modified by researchers included time violations, excess transit, start time, and grouping routes according to priority. Adjusting these constraints let researchers manipulate the program to generate efficient, simple, and realistic routes. Combining Network Analyst tools and researchers' knowledge to solve snowplow routing problems is a very heuristic process.

- Officials will require more preparation time to account for new routes and routing options that may be counterintuitive. Furthermore, ArcGIS can provide turn-by-turn directions. This could be especially helpful on new routes or routes that are unintuitive. District officials should facilitate the coordination effort and understand how the optimized routes work together.

- Analysis assumed that snowplows traveled on an empty road at constant speed. Although not likely, trucks in some cities may experience delays if there is heavy traffic. Conservative estimates in other areas made up for the chance of this occurrence.

- The analysis excluded lane widths. Including this attribute created too many segments for the model to optimize efficiently and did not affect the choice of routes. 


\section{Next Steps}

As this research moves forward, a few additions will likely greatly improve the optimization. Preliminary results show that county-level route optimizations can further improve by allowing trucks to cross county lines. Furthermore, optimizations are expected to yield even greater improvements when making districtlevel assessments.

More improvements to the optimization could be realized by moving the salt and brine facility to a more centralized location. In some cases, the salt and brine depot is located in a non-central location causing an increase in dead head time. Minimizing dead head time is a secondary measure of optimization, but significant nonetheless.

This research has only been analyzed in four counties thus far. Implementation will be tested during the next winter season during snow and ice events. It is expected that county-level route optimizations will continue to have a positive effect on cost savings for KYTC, and the rest of the state stands to benefit from the procedure. 


\section{References}

1. Sugumaran, R., M. Salim, T. Strauss, and C. Fulcher. Web-based Implementation of a Winter Maintenance Support System Using GIS and Remote Sensing. Midwest Transportation Consortium. MTC Project 2003-05. May 2005. Accessed Nov 2016.

2. Perrier, N., A. Langevin, and C. Amaya. Vehicle Routing for Urban Snow Plowing Operations. Transportation Science, Vol 42, No. 1, 2008, pp. 44-56. http://trid.trb.org/view/851395

3. Gang, L., Y. Ge, T. Z. Qiu, and H. R. Soleymani. Report 13-0491: Vehicle Routing of Urban Snow Plowing Operations: Case Study for City of Edmonton, Canada. Transportation Research Board, Washington, D.C., 2013. http://trid.trb.org/view/1240524

4. Alfelor, Roemer, and C. Y. D. Yang. Managing Traffic Operations During Adverse Weather Events. Publication FHWA-HRT-11-002. FHWA, U.S. Department of Transportation, 2011. http://www.fhwa.dot.gov/publications/publicroads/11janfeb/01.cfm

5. Wooseung, J., J. Noble, and C. Nemmers. Optimizing Winter/Snow Removal Operations in MoDOT St. Louis District - Includes Outcome Based Evaluation of Operations. University of Missouri. Cmr1200-007. Oct 2011. Accessed Nov 2016.

6. Hajibabai, L., S. M. Nourbakhsh, Y. Ouyang, and F. Peng. Report 13-0795: Snowplow Routing Optimization Under Resource Constraints: Formulation, Algorithm, and Decision-Support System. Transportation Research Board, Washington, D.C., 2013. http://trid.trb.org/view/1240666

7. Dowds, J., J. Sullivan, D. Scott, and D. Novak. Report 2013-12: Optimization of Snow Removal in Vermont. Transportation Research Board, Washington, D.C., 2013. https://trid.trb.org/view.aspx?id=1331821

8. Winter Maintenance: Checking Priorities. Roads \& Bridges, June 2013. http://www.roadsbridges.com/winter-maintenance-checking-priorities. Accessed Nov 2016.

9. E.R. Green, C. Blackden, M.A. Fields. Spatial Database for Intersections, 95th Annual TRB, Transportation Research Board, Washington, DC, 2016 